\title{
Melatonin decreases cocaine-induced locomotor activity in pinealectomized rats
}

\author{
Susana Barbosa-Méndez, Alberto Salazar-Juárez iD \\ Laboratorio de Neurofarmacología Conductual, Microcirugía y Terapéutica Experimental, Subdirección de Investigaciones Clínicas, Instituto \\ Nacional de Psiquiatría, Ciudad de México, Mexico.
}

\begin{abstract}
Objective: Several studies have shown that the time of day regulates the reinforcing effects of cocaine. Additionally, melatonin and its $\mathrm{MT}_{1}$ and $\mathrm{MT}_{2}$ receptors have been found to participate in modulation of the reinforcing effects of such addictive drugs as cocaine. Loss of the diurnal variation in cocaine-induced locomotor sensitization and cocaine-induced place preference has been identified in pinealectomized mice. In addition, several studies in rodents have shown that administration of melatonin decreased the reinforcing effects of cocaine. The objective of this study was to evaluate the effect of melatonin on cocaine-induced locomotor activity in pinealectomized rats at different times of day (zeitgeber time [ZT]4, ZT10, ZT16, and ZT22).

Methods: Naïve, pinealectomized Wistar rats received cocaine at different times of day. Melatonin was administered 30 min before cocaine; luzindole was administered 15 min prior to melatonin and $45 \mathrm{~min}$ before cocaine. After administration of each treatment, locomotor activity for each animal was recorded for a total of $30 \mathrm{~min}$. Pinealectomy was confirmed at the end of the experiment through melatonin quantitation by ELISA.

Results: Cocaine-induced locomotor activity varied according to the time of day. Continuous lighting and pinealectomy increased cocaine-induced locomotor activity. Melatonin administration decreased cocaine-induced locomotor activity in naïve and pinealectomized rats at different times of day. Luzindole blocked the melatonin-induced reduction in cocaine-induced locomotor activity in pinealectomized rats.

Conclusion: Given its ability to mitigate various reinforcing effects of cocaine, melatonin could be a useful therapy for cocaine abuse.
\end{abstract}

Keywords: Melatonin; cocaine; locomotor activity; diurnal rhythms; luzindole

\section{Introduction}

Substance use disorders (SUD) constitute an important public health problem worldwide, affecting a great number of individuals. SUD is characterized by a high propensity for relapse. ${ }^{1}$ Several studies in humans have reported that SUD is associated with disruptions in multiple behavioral and physiological circadian rhythms, including sleep, eating patterns, corticosterone, glucose, and endocrine fluctuations. ${ }^{2-4}$ Other studies have found that chronic cocaine abusers show seasonal patterns of craving and substance abuse. ${ }^{5}$

Studies in animals have shown that the time of day regulates the reinforcing effects of psychostimulants such as cocaine $e^{6,7}$ and nicotine ${ }^{8}$ and even of opioids such as morphine. ${ }^{9}$ Pioneering studies by Abarca et al. ${ }^{6}$ demonstrated that cocaine-induced locomotor sensitization varies according to the day/night cycle. Other authors have reported that reinstatement of cocaine-induced place preference increases during the day. ${ }^{10,11}$ In addition,

Correspondence: Alberto Salazar-Juárez, Laboratorio de Neurofarmacología Conductual, Microcirugía y Terapéutica Experimental, Subdirección de Investigaciones Clínicas, Instituto Nacional de Psiquiatría, Ciudad de México, 14370, Mexico.

E-mail: azazel_vamp@yahoo.com.mx

Submitted Jan 10 2019, accepted Sep 13 2019, Epub Dec 202019. cocaine self-administration has been found to vary with time of day. ${ }^{12}$

Other studies have described diurnal and circadian variations in dopamine levels, ${ }^{13,14}$ dopamine transporters (DAT), tyrosine hydroxylase (TH), ${ }^{15}$ and dopamine clearance $(D C)^{16}$ in the caudate, nucleus accumbens (NAcc), and prefrontal cortex (PFC) in rats.

The pineal gland is a brain structure capable of transducing environmental lighting conditions into an endogenous hormonal signal by synthesizing and releasing melatonin. This process which occurs under the control of the endogenous biological clock (hypothalamic suprachiasmatic nuclei [SCN]), which times melatonin synthesis to occur daily in synchrony with the light/dark cycle, peaking during the dark period and declining to almost negligible levels during daytime. Melatonin plays an important role in the circadian modulation of behavioral and physiological functions. ${ }^{17-19}$

As mentioned above, the production and release of melatonin peak at night and fall during the day. ${ }^{18,19}$

How to cite this article: Barbosa-Méndez $S$, Salazar-Juárez A. Melatonin decreases cocaine-induced locomotor activity in pinealectomized rats. Braz J Psychiatry. 2020;42:295-308. http://dx.doi. org/10.1590/1516-4446-2018-0400 
However, surgical removal of the pineal gland (pinealectomy [Pnx]) results in inability to synthesize and release melatonin. ${ }^{20,21}$ This model of experimentally induced melatonin deficiency has been a very useful tool for studying the role of melatonin in the etiopathogenesis of several brain disorders, including anxiety, mood disorders, addictions, and Alzheimer's disease.

The $\mathrm{MT}_{1}$ and $\mathrm{MT}_{2}$ melatonin receptors are responsible for some of the effects of melatonin at the cerebral level, such as the inhibition of dopamine release in the retina and mesencephalic dopamine areas, the inhibition of neuronal firing in the SCN, and the regulation of testicular and ovarian function through inhibition of prolactin and testosterone secretion; they also participate in the regulation of cortisol secretion, as well as in regulation of oxytocin receptor gene expression and, consequently, uterine contractility. At the peripheral level, $\mathrm{MT}_{1}$ and $\mathrm{MT}_{2}$ receptors participate in cardiovascular regulation by modulating vasoconstriction and vasodilation; in regulation of the immune response, by increasing splenocyte proliferation; and in the regulation of glucose homeostasis, through inhibition of insulin secretion and upregulation of leptin production. ${ }^{17,22,23}$

A number of studies have identified melatonin receptors in several regions of the dopaminergic system, ${ }^{24,25}$ and described diurnal variations in active $\mathrm{MT}_{1}$ receptor levels in the NAcc and the ventral tegmental area (VTA), where such levels are higher during the night (zeitgeber time $[\mathrm{ZT}] 21)$ and lower during the day (ZT5). ${ }^{25}$

Other research has studied how melatonin and its receptors modulate the reinforcing effects of addictive drugs such as cocaine ${ }^{26}$ nicotine ${ }^{27}$ and amphetamines. ${ }^{28}$ These studies found a loss of diurnal variation in cocaineinduced locomotor sensitization and conditioned place preference (CPP) in melatonin-deficient pinealectomized $\mathrm{C} 3 \mathrm{H} / \mathrm{HeJ}$ mice ${ }^{10,29}$ Furthermore, in $\mathrm{C} 3 \mathrm{H} / \mathrm{HeN}$ mice, cocaine induces locomotor sensitization during the light phase, when melatonin levels are low, whereas at night, when melatonin levels are high, this effect is blunted. ${ }^{10}$ No such diurnal variation is found in C57BL/6J mice, which are considered melatonin-deficient due to disruption of an arylalkylamine $\mathrm{N}$-acetyltransferase gene (the rate-limiting enzyme in melatonin synthesis). ${ }^{11}$

Given the large body of evidence suggesting that melatonin regulates diurnal cocaine-induced variations ${ }^{10,11,29}$ and decreases the reinforcing effects of nicotine ${ }^{27}$ and alcohol $^{30}$ in mice, this study sought to explore the effect of melatonin administration at different times of day (ZT4, ZT10, ZT16, and ZT22) on cocaine-induced locomotor activity in naïve and pinealectomized rats. We hypothesized that melatonin administration would decrease such activity.

\section{Methods}

\section{Animals}

Male Wistar rats (age 8 weeks, weight 250-280 g) were used for this study. Rats were housed in groups of four in standard plastic cages $(57 \times 35 \times 20 \mathrm{~cm})$, in a colony room kept at a constant temperature $\left(21 \pm 2{ }^{\circ} \mathrm{C}\right)$ and humidity (40-50\%), either on a 12:12-h light/dark cycle (400 lux of white light during the light phase and complete darkness during the dark phase) or under continuous light (L/L) (lights on $24 \mathrm{~h} /$ day) to induce functional Pnx. Throughout the study, to reduce disturbance to a minimum and the likelihood of inadvertent nonphotic entrainment among rats held in L/L, routine cleaning was carried out every 1 to 2 days at random times of day.

For the 12:12 light-dark (L/D) and L/L cycles, the time of day was expressed as ZT, as follows: at 8 a.m., the lights are turned on; this time point is set as ZTO. At 8 p.m., the lights are turned off; this time point is set as ZT12. ZT24 is ZTO of the next day.

All animals had continuous access to water and rodent chow pellets, except during experimental sessions.

\section{Drugs}

Cocaine hydrochloride (COC) was kindly donated by the Mexican government, under strict regulatory controls. All drugs used in experimental animals were kept under official surveillance (COFEPRIS, LC-0004-2003). Melatonin (Sigma-Aldrich, St. Louis, MO, USA) and luzindole (Tocris Cookson, Ballwin, MO, USA) were purchased after obtaining the required regulatory permission, as per official guidelines (COFEPRIS-2016, Mexico). COC was dissolved in sterile saline (SAL) $(0.9 \% \mathrm{NaCl}$, SigmaAldrich, St. Louis, MO, USA). Melatonin and luzindole were dissolved in ethanol and diluted with SAL. The final ethanol concentration was $0.1 \%$ in both vehicle and melatonin solution. The solutions were compounded extemporaneously before intraperitoneal (i.p.) administration to the animals. During the experiments, all solutions were maintained at $4{ }^{\circ} \mathrm{C}$. Melatonin and luzindole solutions were protected from light exposure by storage in black bottles. SAL was used as control in all experiments.

To ascertain whether melatonin could prevent the effects of cocaine, it was administered 30 min before COC or SAL. To ascertain whether luzindole, a selective $\mathrm{MT}_{1}$ and $\mathrm{MT}_{2}$ melatonin receptor antagonist, attenuated the ability of melatonin to decrease cocaine-induced locomotor effects, it was administered $15 \mathrm{~min}$ prior to melatonin. The volume injected into the animals depended on their body weight (BW) in grams $(100 \mathrm{~mL})$.

\section{Dose selection}

Determination of the optimal dose of cocaine was based on previous studies, which reported that $10 \mathrm{mg} / \mathrm{kg}$ cocaine produces a robust increase in locomotor activity and behavioral sensitization. ${ }^{23}$ This dose of cocaine does not cause seizures or lethality. ${ }^{31-35}$

The optimal melatonin dose $(30 \mathrm{mg} / \mathrm{kg})$ was determined in accordance with previous reports indicating that $30 \mathrm{mg} / \mathrm{kg}$ melatonin decreases cocaine-induced locomotor activity in rats. ${ }^{36}$ We selected a $30 \mathrm{mg} / \mathrm{kg}$ dose of luzindole because it has been shown to block melatonin receptor function in rodents. ${ }^{37}$ 


\section{Pinealectomy}

For surgical removal of the pineal gland and sham surgery, rats were weighed, anesthetized with ketamine $\mathrm{HCl}(90$ $\mathrm{mg} / \mathrm{kg}$, i.p.) and xylazine (5 mg/kg, i.p.), and secured in a stereotaxic instrument. A sagittal opening was made on the scalp. After pushing the skin aside to expose the lambdoid suture, a disk-shaped piece of bone was gently resected with a drill to allow visualization of the transverse and sagittal sinuses. The cerebral veins were carefully deflected to minimize blood loss. Any bleeding was controlled with Gelfoam (The Upjohn Co. Kalamazoo, U.S.).

The superficial pineal gland, located below the posterior venous sinus confluence, was removed using fine forceps. After Pnx, the disk-shaped bone flap was returned to the skull and the scalp was sutured with cotton thread once temporary hemostasis had been achieved. After surgery, each animal received a single injection of penicillin $(120,000 \mathrm{IU} / \mathrm{kg}$, intramuscular [IM]) and was monitored for potential postoperative complications. In sham-operated rats $(P n x-S)$, all of the aforementioned procedures were performed, except for removal of the pineal gland.

At the end of each procedure, histological examination of each pineal gland was carried out to verify completeness of Pnx and absence of damage to nearby brain areas.

\section{Melatonin enzyme-linked immunosorbent assay (ELISA)}

Melatonin levels were determined in plasma samples collected from the brachial vein at ZT22 (dark phase). Briefly, $500 \mu \mathrm{L}$ samples of blood were collected into small heparinized vials and kept on ice until centrifugation (1,000 rpm for $5-10 \mathrm{~min}$ at $\left.4{ }^{\circ} \mathrm{C}\right)$ to allow for extraction of plasma. Tubes containing plasma were wrapped in aluminum foil to prevent light-induced degradation, and stored at $-80{ }^{\circ} \mathrm{C}$ until analysis. Melatonin levels were measured with by a commercial ELISA kit (Enzo Life Sciences Inc., New York, USA), again taking all necessary measures to prevent photodegradation. The melatonin concentration was analyzed as per the manufacturer's instructions.

\section{Behavioral sensitization procedure}

\section{Apparatus}

For assessment of locomotor activity, animals were placed in transparent Plexiglas activity chambers $(50 \times 50 \times 30$ $\mathrm{cm}$ ) linked to a personal computer (PC). Each activity chamber was surrounded by a $16 \times 16$ photocell beam array located $3 \mathrm{~cm}$ from the floor surface to scan locomotor activity (OMNIALVA, Instruments, Ciudad de México, Mexico). Photobeam interruptions were automatically quantified with OABiomed software v. 1.1 and analyzed subsequently. Locomotor activity was defined as the interruption of consecutive photobeams (OMNIALVA, Instruments, Ciudad de México, Mexico).

\section{Procedure}

Spontaneous locomotor activity was estimated with a standard protocol. ${ }^{35}$ Animals were habituated to the activity chambers in three 30-min sessions and were randomly assigned to different pharmacotherapy groups. Locomotor activity was recorded for $30 \mathrm{~min}$. The rats were returned to their home cages after each experimental session had been completed.

\section{Experimental procedures}

This study used 480 male Wistar rats, which were allocated across five experimental groups. For Experiments 1 and 2, we used 64 animals that were further divided into eight experimental groups $(n=8)$; for Experiment 3, we used 128 animals in 16 groups $(n=8)$; for Experiments 4 and 5 , we used 160 animals in 20 groups $(n=8)$. Each experimental group received a different pharmacological treatment.

Experiment 1: Diurnal differences in cocaine-induced locomotor activity

This experiment included two phases: the light phase, which included measurements at two time points (ZT4 and ZT10), and the dark phase, which included measurements at ZT16 and ZT22. Rats in this experiment were divided into groups according to the $\mathrm{ZT}$ at which cocaine was given.

After 3 days of habituation, at ZT4, the SAL and cocaine groups received $\mathrm{SAL}$ solution $(0.9 \% \mathrm{NaCl}$, i.p.) and COC (10 mg/kg, i.p.), respectively, for 10 days: during the light phase at ZT4 and ZT10, and during the dark phase at ZT16 and ZT22. After administration of each treatment, locomotor activity for each animal was recorded for a total of $30 \mathrm{~min}$ (Figure 1A). The rats tested at a given time of day were not tested again at any other time.

Experiment 2: Continuous lighting increases cocaineinduced locomotor activity

Experiment 2 evaluated the effect of continuous lighting as per the above-described protocol. The rats in this experiment were divided into groups according to the ZT when cocaine was given.

After 3 days of habituation, at ZT4, the SAL and COC groups received SAL solution $(0.9 \% \mathrm{NaCl}$, i.p.) and $\mathrm{COC}$ (10 $\mathrm{mg} / \mathrm{kg}$, i.p.), respectively, for 10 days at ZT4 and ZT10, then at ZT16 and ZT22. After administration of each treatment, locomotor activity for each animal was recorded for a total of $30 \mathrm{~min}$ (Figure 2A). At the end of the experiment, serum melatonin levels were analyzed by ELISA as described above.

Experiment 3: Pinealectomy enhances cocaine-induced locomotor activity

Experiment 3 evaluated the effect of Pnx as per the protocol described in Experiment 1. The rats were divided into groups according to the ZT when cocaine was given. This experiment consisted of three phases: phase I, or the cocaine-impregnation phase, which lasted 5 days; phase II, or the Pnx phase, which lasted 5 days; and phase III, or the post-Pnx phase, which lasted 10 days (Figure $3 A$ ). 
A

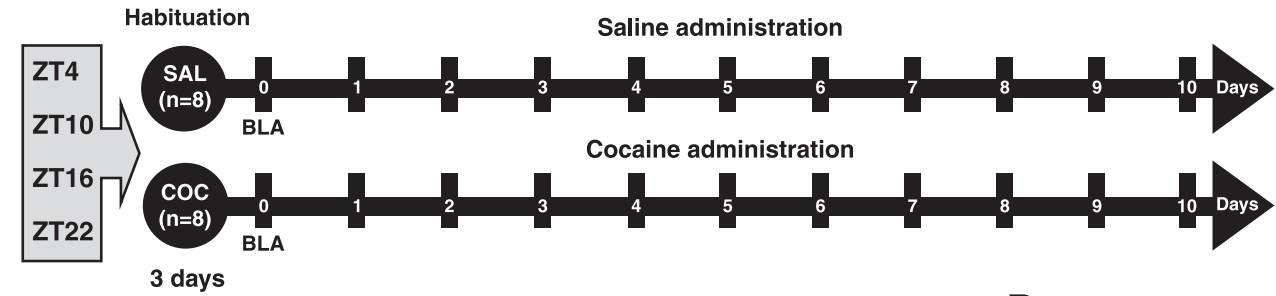

B

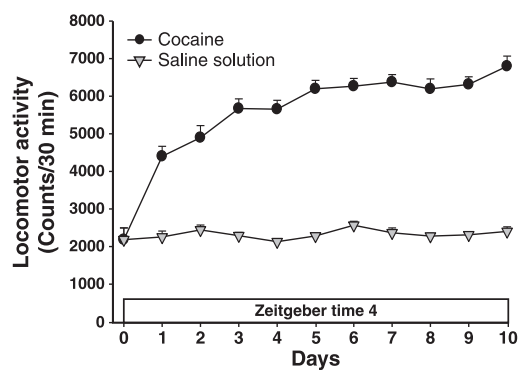

C

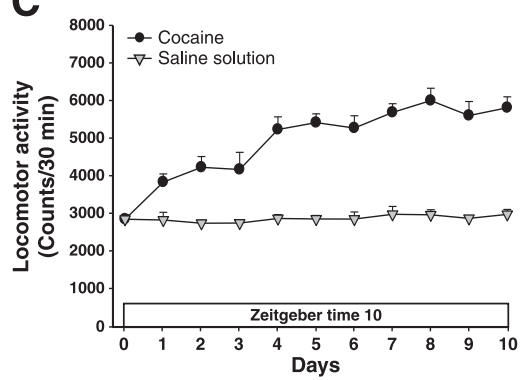

$\mathbf{F}$

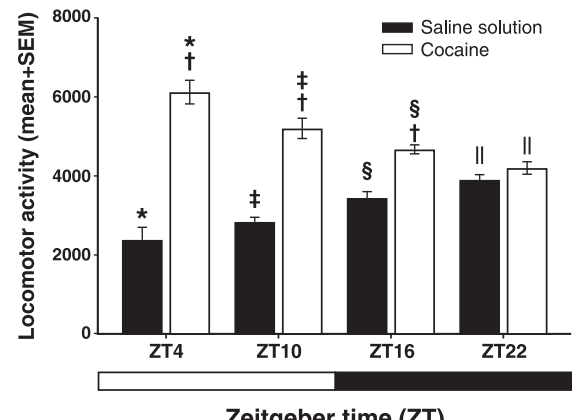

Zeitgeber time (ZT)

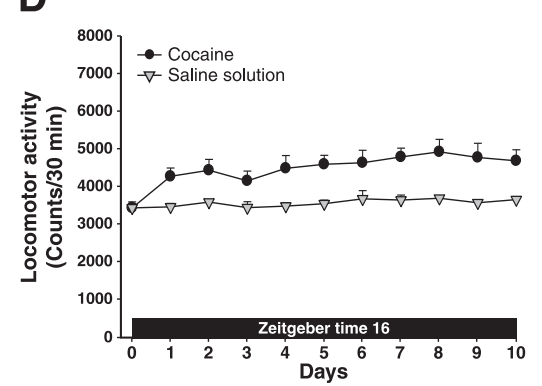

E

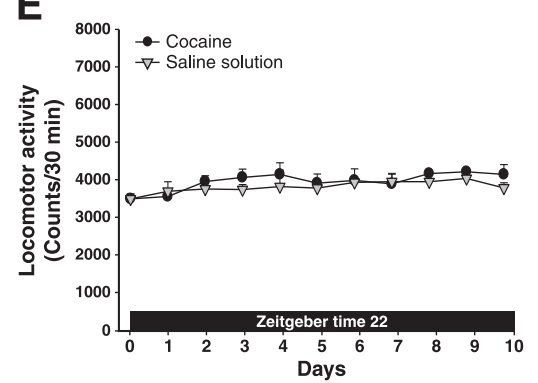

Figure 1 Diurnal variation in cocaine-induced locomotor activity. A) Experiment timeline. B-E) Cocaine-induced locomotor activity at Zeitgeber time (ZT)4, ZT10, ZT16, and ZT22. F) Mean (10 days) locomotor activity ( \pm standard error of the mean [SEM]) by group ( $n=8$ animals per group) at different times of day. White bars correspond to the administration of saline (SAL), and black bars, to the administration of cocaine (COC). The zero time point corresponds to basal locomotor activity (BLA). * Significant $(p<0.01)$ effects of COC on locomotor activity compared to the SAL group. ${ }^{\dagger}$ Significant $(p<0.01)$ effects of COC or SAL on locomotor activity at ZT4 compared to the COC group at ZT10. ${ }^{\ddagger}$ Significant $(p<0.01)$ effects of COC or SAL on locomotor activity at ZT16 compared to the COC group at ZT22. ${ }^{\S}$ Significant $(p<0.01)$ effects of COC or SAL on locomotor activity at ZT10 compared to the COC group at ZT16. "Significant $(p<0.01)$ effects of COC or SAL on locomotor activity at ZT22 compared to ZT4, determined by a two-way analysis of variance (ANOVA) followed by Tukey's tests.

After 3 days of habituation, during the impregnation phase, the Pnx-S (Pnx-S-saL; Pnx-S-coc) and the Pnx (Pnx-sAL; Pnx-coc) groups received SAL (0.9\% NaCl, i.p.) and COC (10 $\mathrm{mg} / \mathrm{kg}$, i.p.) for 5 days. Subsequently, during the Pnx phase, the rats underwent sham or complete Pnx. All animals were monitored for possible postoperative complications. In the post-Pnx phase, animals received SAL or COC for 10 days at ZT4 and ZT10, then at ZT16 and ZT22. After administration of each treatment, locomotor activity for each animal was recorded for a total of 30 min (Figure 3A). Pnx was confirmed at the end of the experiment by testing for melatonin (ELISA) on serum samples collected during the dark period.

Experiment 4: Melatonin reduces cocaine-induced locomotor activity in pinealectomized rats

Experiment 4 evaluated the effect of melatonin as per the protocol described in Experiment 1. The rats were divided into groups according to the ZT when cocaine was given.
This experiment consisted of four phases: phase I, or the cocaine-impregnation phase, which lasted 5 days; phase II, or the Pnx phase, which lasted 5 days; phase III, or the post-Pnx phase, which lasted 10 days; and phase IV, or the melatonin phase, which lasted 10 consecutive days (Figure 4A).

After 3 days of habituation, during the impregnation and post-Pnx phases, the Pnx-S (Pnx-S-SAL+SAL, PnxS- $-O C+$ COC, PnX-S-SAL+MEL, PnX-S-COC+MEL) and Pnx (PnX-sal+SAL, Pnx-COC+COC, PnX-SAL + MEL, Pnx-COC $+\mathrm{MEL})$ groups received SAL $(0.9 \% \mathrm{NaCl}$, i.p. $)$ and $\mathrm{COC}$ $(10 \mathrm{mg} / \mathrm{kg}$, i.p.). During the Pnx phase, the rats underwent sham or complete Pnx, All animals were monitored for possible post-surgical complications. During the melatonin phase, the rats received SAL or melatonin $30 \mathrm{~min}$ before COC or SAL for 10 days at ZT4 and ZT10, then at ZT16 and ZT22. After administration of each treatment, locomotor activity for each animal was recorded for a total of $30 \mathrm{~min}$ (Figure 4A). Pnx was confirmed at the end of the experiment by melatonin ELISA. 
A

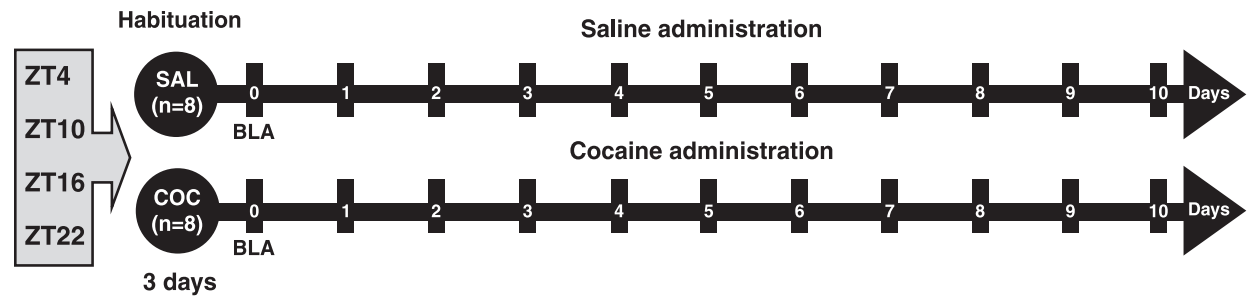

B

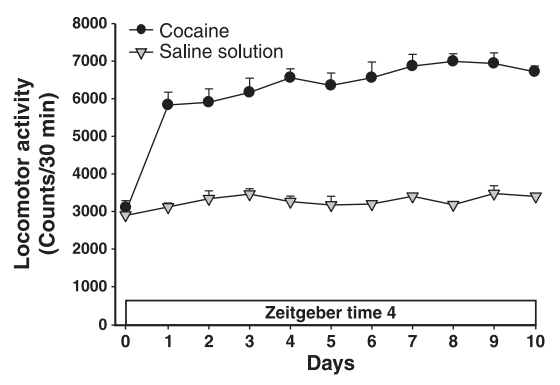

C

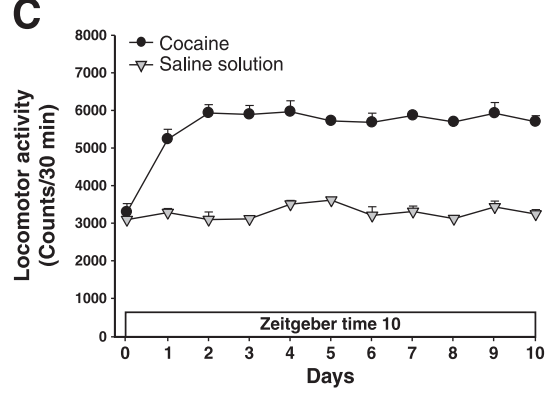

F

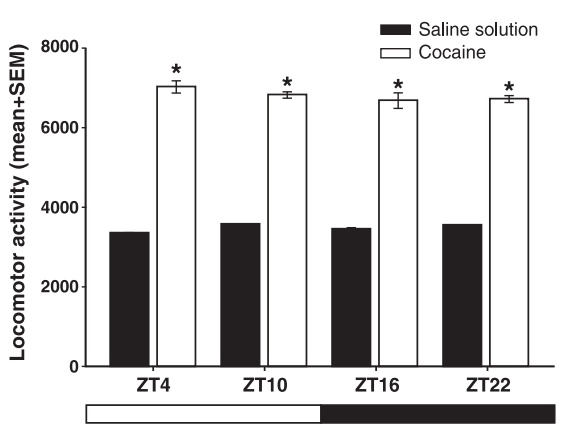

Zeitgeber time (ZT)

G

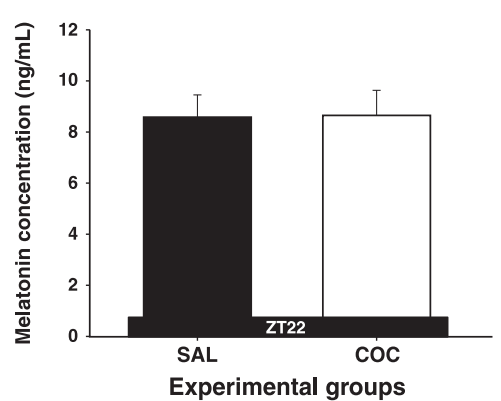

D

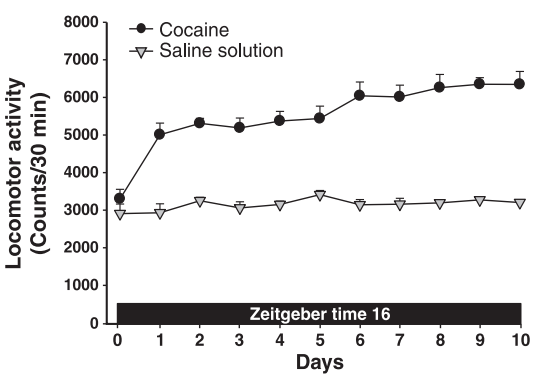

E

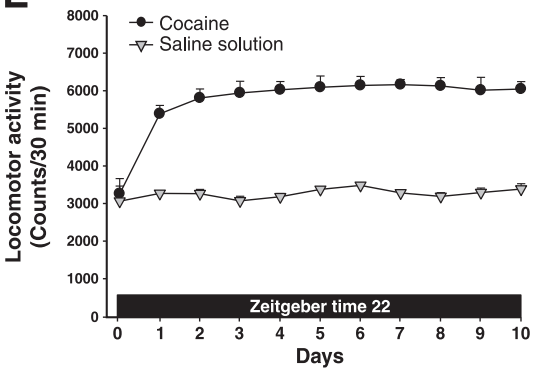

Figure 2 Continuous lighting enhances cocaine-induced locomotor activity. A) Experiment timeline. B-E) Effect of continuous lighting on locomotor activity induced by cocaine at Zeitgeber time (ZT)4, ZT10, ZT16, and ZT22. White bars correspond to the administration of saline (SAL) and black bars correspond to the administration of cocaine (COC). The zero time point corresponds to the basal locomotor activity (BLA). F) Mean (10 days) locomotor activity ( \pm standard error of the mean [SEM]) by group ( $n=8$ animals per group) at different times of day. *Significant $(p<0.01)$ effects of COC on locomotor activity compared to the SAL group, determined by a two-way analysis of variance (ANOVA) followed by Tukey's tests. Inset shows the effect of continuous light $(\mathrm{L} / \mathrm{L})$ on the mean concentration \pm SEM of serum melatonin. ${ }^{\dagger}$ Significant $(p<0.01)$ effects induced by $\mathrm{L} / \mathrm{L}$ on serum melatonin levels in the SAL and COC groups determined by one-way ANOVA followed by Tukey's tests (not observed).

Experiment 5: Luzindole blocks melatonin-induced reduction of cocaine-induced locomotor activity in pinealectomized rats

Experiment 5 evaluated the effect of luzindole as per the protocol described in Experiment 4. The rats in this experiment were divided into four groups, according to the ZT at which cocaine was given. This experiment consisted of five experimental phases: phase I, or the cocaine-impregnation phase, which lasted 5 days; phase II, or the Pnx phase, which lasted 5 days; phase III, or the post-Pnx phase, which lasted 10 days; phase IV, or the melatonin phase, which lasted 10 consecutive days; and phase $\mathrm{V}$, or the antagonist phase, which also lasted 5 consecutive days (Figure 5A).
After 3 days of habituation, the Pnx-S (Pnx-S-SAL + SAL + MEL, Pnx-S-COC + SAL + MEL) and Pnx (PnX-SAL + SAL + MEL, $P n x-C O C+S A L+M E L)$ groups received $S A L$ or $C O C$ during the impregnation and post-Pnx phases. For the melatonin phase, the rats received melatonin 30 min before COC or SAL for 10 days. For the antagonist phase, all groups received $S A L 15$ min before melatonin and melatonin 30 min before COC or SAL at ZT4 and ZT10 and ZT16 and ZT22.

Rats in the Pnx-S (Pnx-S-SAL+LUZ+MEL, Pnx-S- ${ }_{-}$Coc $+\mathrm{LUZ}+\mathrm{MEL}$ ) and PnX (PnX-SAL + LUZ+MEL, PnX-COC+LUZ $+\mathrm{MEL}$ ) groups, during the impregnation and the post-Pnx phases, received SAL or COC. For the melatonin phase, animals received melatonin 30 min before $\mathrm{COC}$ or $\mathrm{SAL}$ for 10 days. For the antagonist phase, all groups received 
A Cocaine-impregnation phase

Post-pinealectomy phase

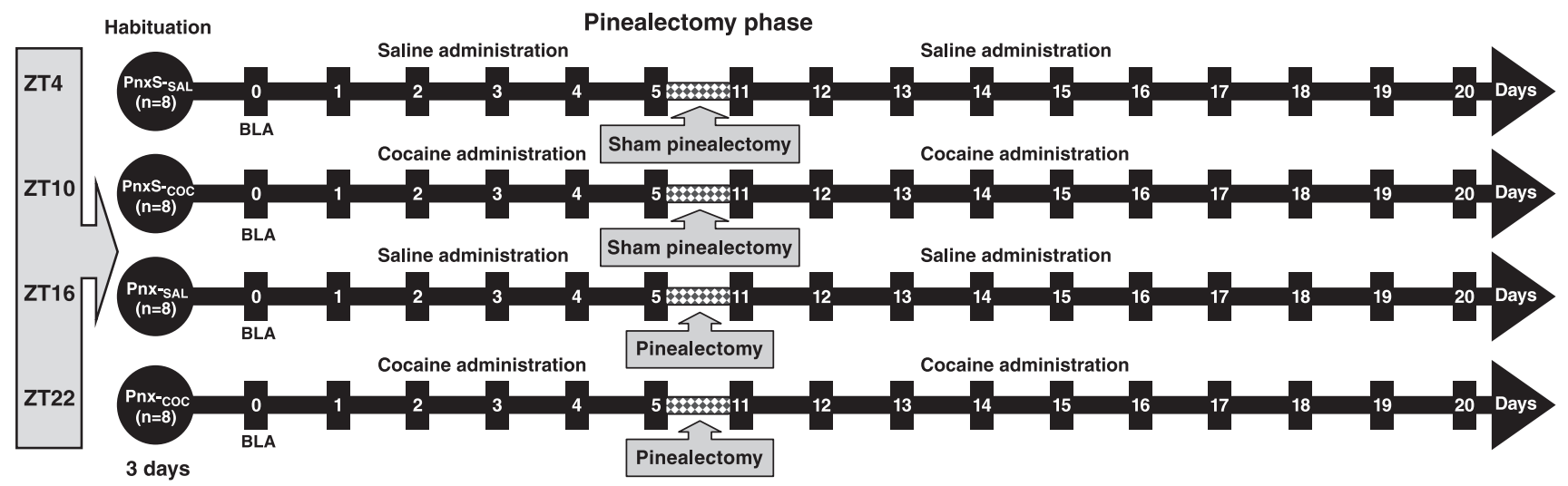

B

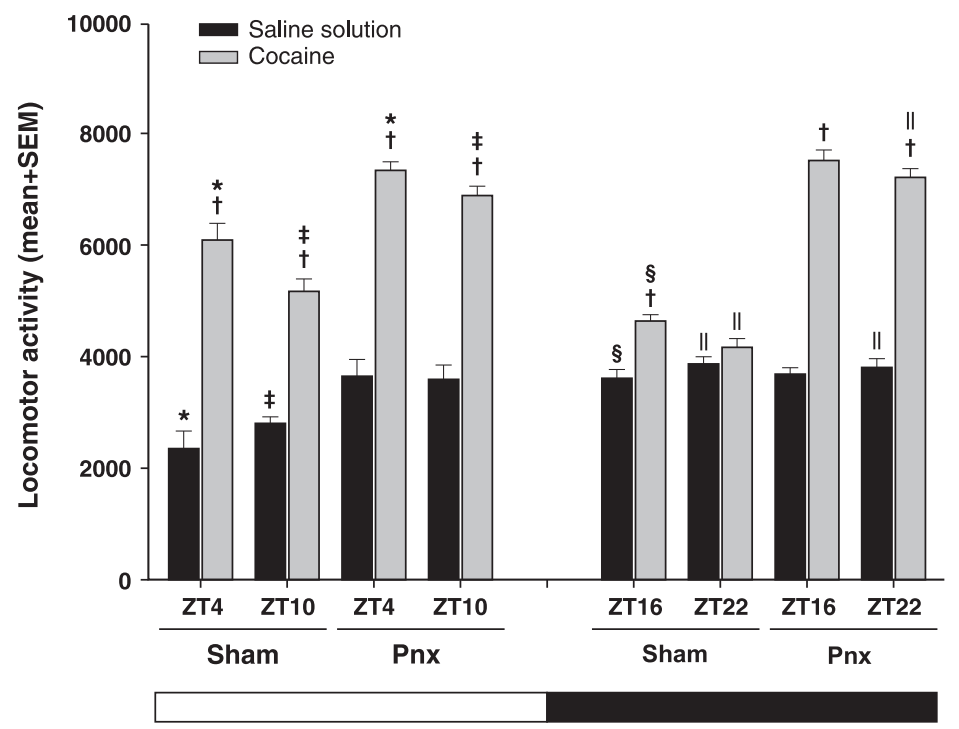

C

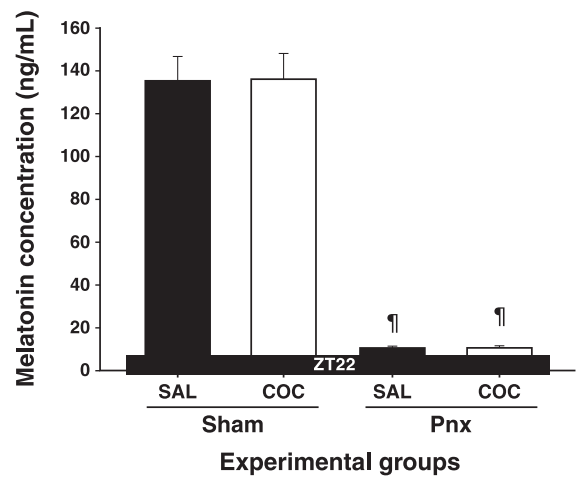

Zeitgeber time (ZT)

Figure 3 Pinealectomy $(\mathrm{Pnx})$ increases cocaine-induced locomotor activity. A) Experiment timeline. The zero time point corresponds to the basal locomotor activity (BLA). B) Mean (10 days) locomotor activity ( \pm standard error of the mean [SEM]) by group ( $\mathrm{n}=8$ animals per group) at ZT4, ZT10, ZT16, and ZT22. White bars correspond to the administration of saline (SAL) and black bars correspond to the administration of cocaine (COC). C) Effect of pinealectomy on the mean concentration \pm SEM of serum melatonin. *Significant $(p<0.01)$ effects of COC on locomotor activity compared to the SAL groups. $\dagger$ Significant $(p<0.01)$ effects of COC or SAL on locomotor activity at ZT4 compared to ZT10. $\$$ Significant $(p<0.01)$ effects

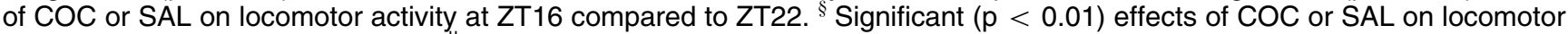
activity at ZT10 compared to ZT16. "Significant $(p<0.01)$ effects of COC or SAL on locomotor activity at ZT22, compared to ZT4, determined by a three-way analysis of variance (ANOVA) followed by Tukey's tests. " Significant ( $p<0.01$ ) effects induced by pinealectomy on serum melatonin levels at ZT22 determined by one-way ANOVA following Tukey's tests.

luzindole $15 \mathrm{~min}$ before melatonin, and melatonin $30 \mathrm{~min}$ before COC (10 mg/kg, i.p.) or SAL, at ZT4 and ZT10, then ZT16 and ZT22. After administration of each treatment, locomotor activity for each animal was recorded for a total of $30 \mathrm{~min}$ (Figure 5A). Pnx was confirmed at the end of the experiment by melatonin ELISA (Melatonin ELISA Kit).

\section{Statistical analysis}

Data were expressed as mean \pm standard error of the mean (SEM). For Experiments 1 and 2, locomotor activity in each group was evaluated with a two-way analysis of variance (ANOVA), with groups (SAL and COC) and time of day (ZT4, ZT10, ZT16, and ZT22) as the betweensubjects factors. If the interaction yielded a significant $F$ value, a post-hoc analysis of differences was performed between groups, followed by an additional Tukey's test. For Experiment 3, we used a three-way ANOVA, with groups (SAL and COC), surgery (sham and complete Pnx), and time of day (ZT4, ZT10, ZT16, and ZT22) as the between-subjects factor, followed by Tukey's test. For Experiments 4 and 5, a four-way ANOVA was carried out, with groups (SAL and $\mathrm{COC})$, treatment 

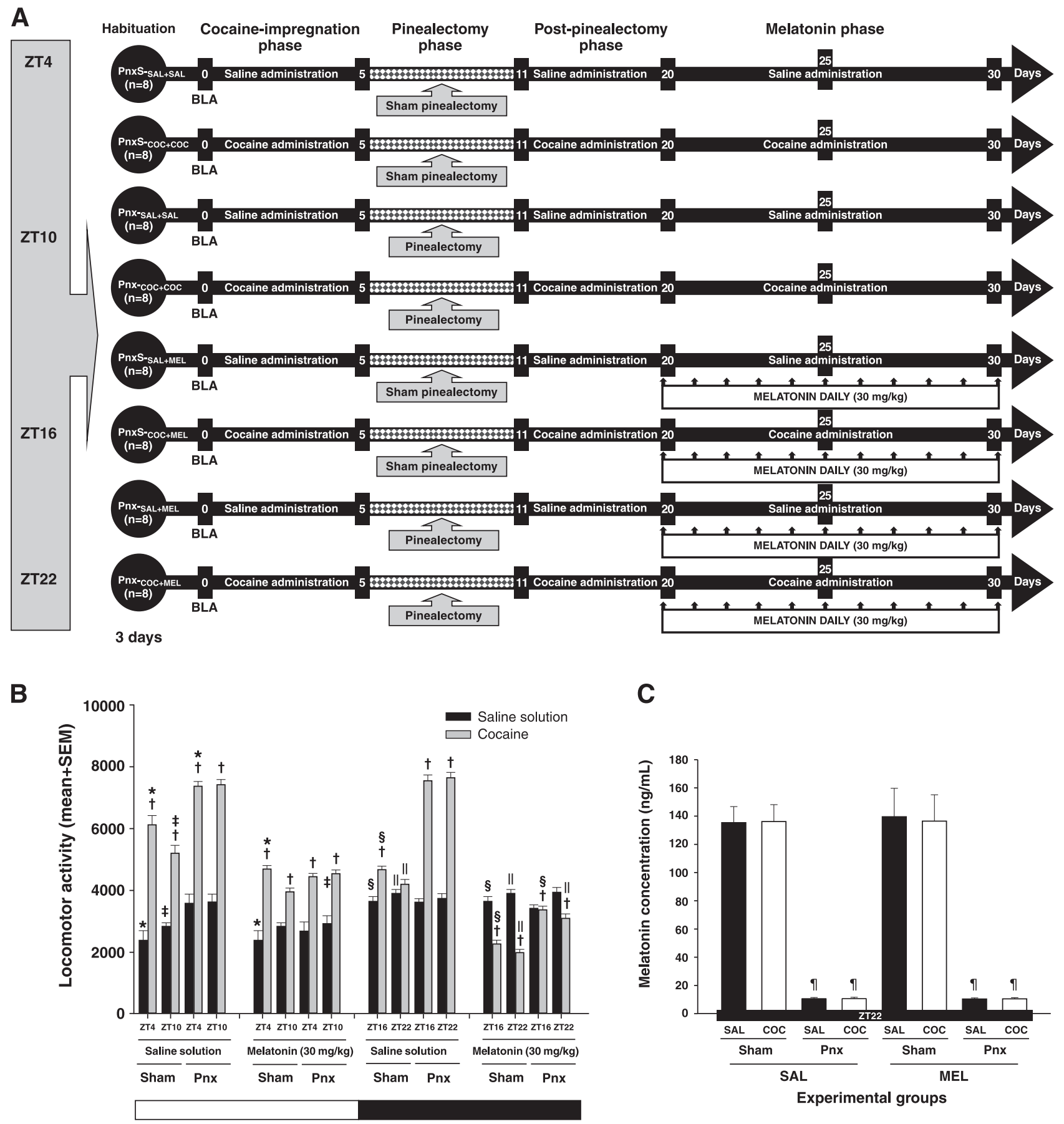

Zeitgeber time (ZT)

Figure 4 Melatonin decreases cocaine-induced locomotor activity in pinealectomized animals. A) Experiment timeline. The zero time point corresponds to the basal locomotor activity (BLA). B) Mean (10 days) locomotor activity ( \pm standard error of the mean [SEM]) by group ( $n=8$ animals per group) at different times of day. White bars correspond to the administration of saline $(\mathrm{SAL})$ and black bars correspond to the administration of cocaine (COC). C) Effect of pinealectomy on the mean concentration \pm SEM of serum melatonin. * Significant $(p<0.01)$ effects of COC on locomotor activity compared to the SAL groups. $\dagger$ Significant $(p<0.01)$ effects of COC or SAL on locomotor activity at ZT4 compared to ZT10. $\$$ Significant $(p<0.01)$ effects of COC or SAL on locomotor activity at ZT16 compared to ZT22. ${ }^{\S}$ Significant $(p<0.01)$ effects of COC or SAL on locomotor activity at ZT10 compared to ZT16. "Significant $(p<0.01)$ effects of COC or SAL on locomotor activity at ZT22 compared to ZT4, determined by a four-way analysis of variance (ANOVA) followed by Tukey's tests. " Significant ( $p<0.01)$ effects induced by pinealectomy on serum melatonin levels in ZT22, determined by one-way ANOVA following Tukey's tests. 


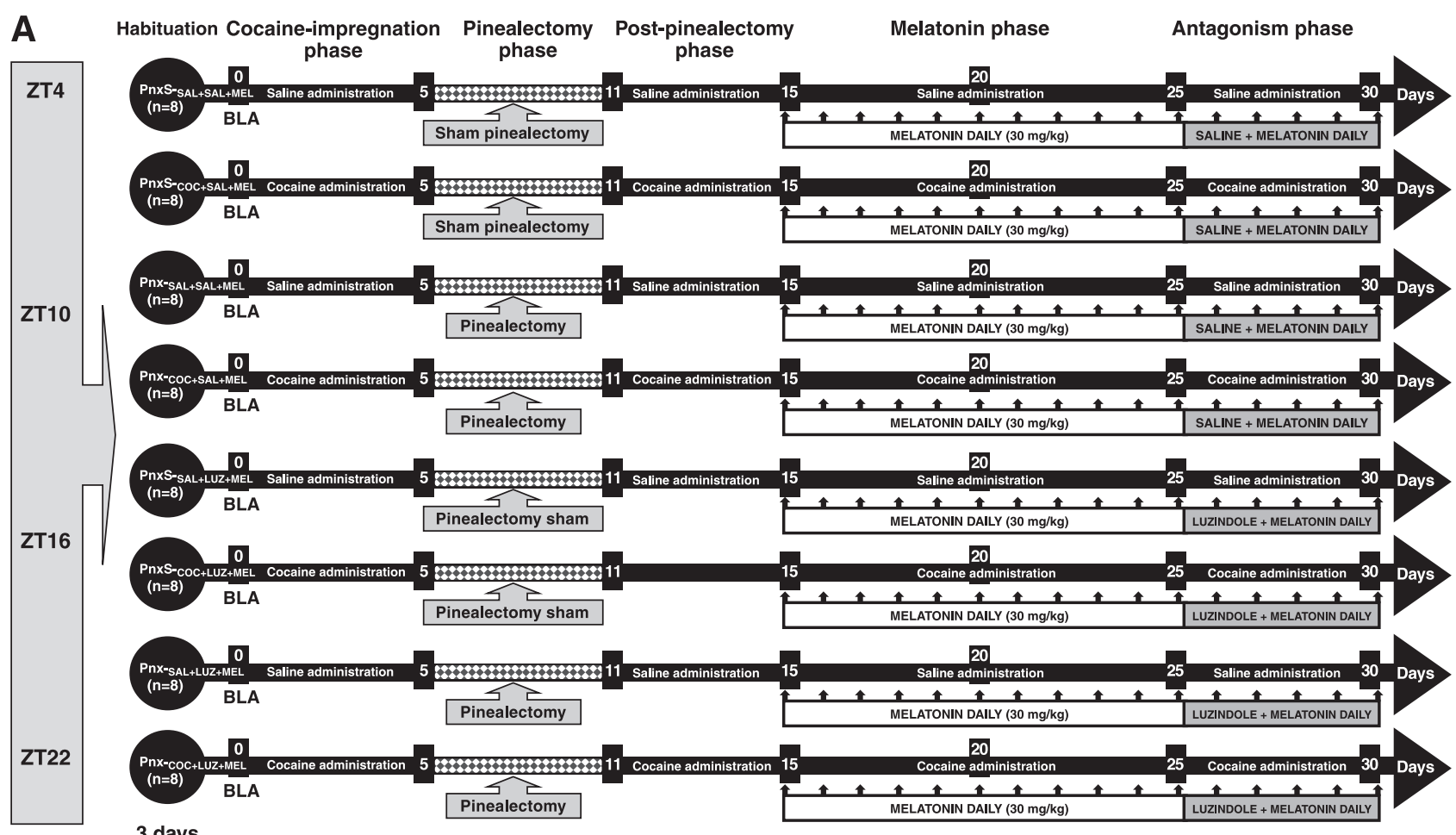

B

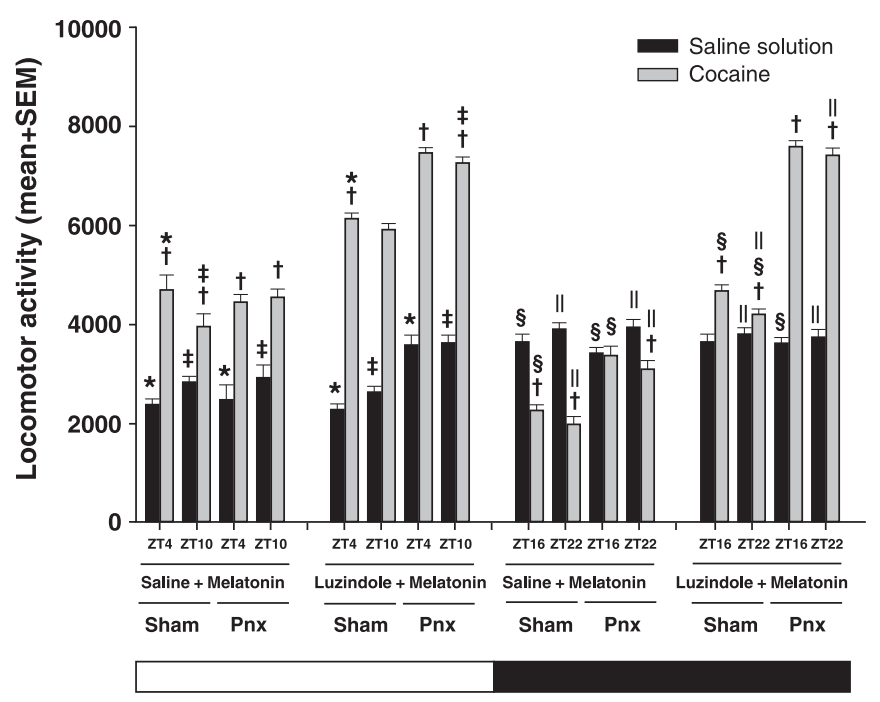

C

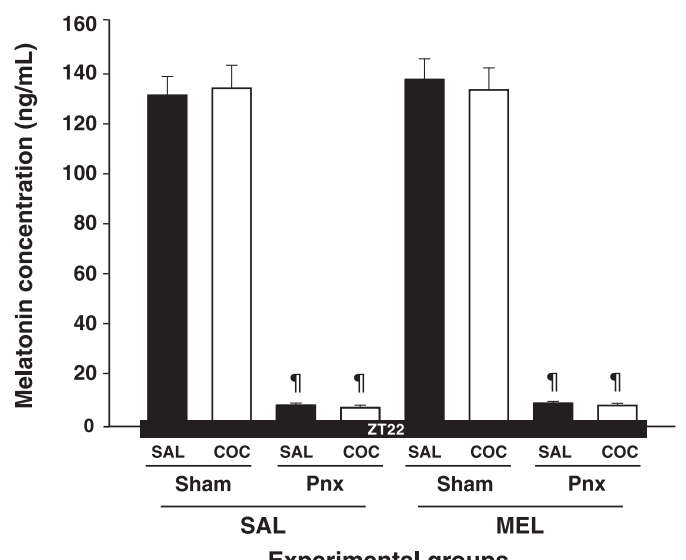

Zeitgeber time (ZT)

Figure 5 Luzindole decreases the effect of melatonin on cocaine-induced locomotor activity in pinealectomized animals. A) Experiment timeline. B) The zero-time point corresponds to the basal locomotor activity (BLA). Mean (5 days) locomotor activity ( \pm standard error of the mean [SEM]) by group ( $n=8$ animals per group) at different times of day. C) White bars correspond to the administration of saline (SAL) and black bars correspond to the administration of cocaine (COC). C) Effect of pinealectomy on the mean concentration \pm SEM of serum melatonin. ${ }^{*}$ Significant $(p<0.01)$ effects of COC on locomotor activity compared to the SAL groups. "Significant $(p<0.01)$ effects of COC or SAL on locomotor activity at ZT4 compared to ZT10. "Significant $(p<0.01)$ effects of COC or SAL on locomotor activity at ZT16 compared to ZT22. ${ }^{\S} p$ Significant $(p<0.01)$ effects of COC or SAL on locomotor activity at ZT10 compared to ZT16. " $p$ Significant $(p<0.01)$ effects of COC or SAL on locomotor activity at ZT22 compared to ZT4, determined by a four-way analysis of variance (ANOVA) followed by Tukey's tests. 'Significant $(p<0.01)$ effects induced by pinealectomy on serum melatonin levels at ZT22, determined by one-way ANOVA followed by Tukey's tests. 
(SAL and melatonin), surgery (sham and complete Pnx), and time of day (ZT4, ZT10, ZT16, and ZT22) as the between-subjects factor, again followed by Tukey's test. For comparison of melatonin levels, one-way ANOVA was used. Statistical significance was accepted at $p<0.05$.

\section{Ethics statement}

The procedures were approved by the institutional animal care and bioethics committee and conducted in strict compliance with the Guide for the Care and Use of Laboratory Animals, published by the National Institutes of Health (NIH). In order to avoid possible side effects due to lighting conditions, pharmacological treatments (clearance), and to avoid physical damage to animals, an independent group design was used in which each animal was used only once.

\section{Results}

\section{Experiment 1: Diurnal differences in cocaine-induced locomotor activity}

Figures $1 \mathrm{~B}$ to $1 \mathrm{E}$ show the effect of time of day $(\mathrm{ZT})$ on cocaine-induced locomotor activity. SAL animals showed an increase in locomotor activity dependent on the time of day, peaking at ZT22. In contrast, the COC animals, which received $10 \mathrm{mg} / \mathrm{kg}$ cocaine, showed a decrease in locomotor activity dependent on the time of day, peaking at ZT4.

Two-way ANOVA found significant differences in the groups vs. time-of-day interaction $\left(F_{3,924}=202.085\right.$, $p<0.0001$ ). Tukey's test revealed differences in locomotor activity in the COC group compared to the SAL group, at ZT4 ( $p<0.001)$, ZT10 ( $p<0.003)$, and ZT16 $(p<0.005)$. However, the statistical analysis found no differences between groups at ZT22 ( $p=0.75)$.

Additionally, the post-hoc test found differences in locomotor activity between the COC and SAL groups at ZT4, compared to that in both groups at ZT22 ( $p<$ 0.001 ). Statistical analysis revealed differences in locomotor activity between the two groups at ZT4 compared to ZT10 ( $p<0.004$ ), at ZT10 compared to ZT16 ( $p<$ $0.002)$, and at ZT16 compared to ZT22 ( $<0.006)$ (Figure 1F). This suggests that cocaine-induced locomotor activity varied according to the time of day.

\section{Experiment 2: Continuous lighting increased cocaine- induced locomotor activity}

Figures $2 \mathrm{~B}$ to $2 \mathrm{E}$ show that, among animals in the SAL and COC groups subjected to continuous lighting, locomotor activity increased regardless of the time of day. The statistical analysis found significant differences (twoway ANOVA; group vs. time-of-day interaction; $F_{3,640}=$ $7.29, p<0.0001$ ) in mean locomotor activity in the COCtreated group, compared to that shown in the SAL group, at ZT4 ( $p<0.001)$, ZT10 ( $p<0.001)$, ZT16 $(p<0.001)$, and ZT22 $(p<0.001)$ (Figure 2F). The post-hoc test, however, found no differences in locomotor activity between the SAL and the COC groups at the times of day evaluated $(p=0.98)$.

Additionally, ELISA showed a decrease in plasma melatonin levels in animals of both groups in ZT22 (Figure 2F inset). One-way ANOVA did not find differences between the groups in this respect $\left(F_{1,15}=5.607\right.$, $p=0.33$ ).

\section{Experiment 3: Pinealectomy increased cocaine-induced} locomotor activity

Figures $6 \mathrm{~A}$ to $6 \mathrm{D}$ show the effect of removal of the pineal gland on cocaine-induced locomotor activity. In the PnxS-SAL and Pnx-S-coc groups, locomotor activity was altered depending on the time of day, as described in Experiment 1. Additionally, melatonin-deficient animals treated with SAL (Pnx-sAL group) showed an increase in locomotor activity, as described in Experiment 2. In contrast, the pinealectomized animals treated with cocaine (Pnx-coc group) showed an enhanced increase in cocaine-induced locomotor activity at ZT4, ZT10, ZT16, and ZT22.

A three-way ANOVA found differences between the group vs. surgery vs. time-of-day interactions $\left(F_{3,1280}=\right.$ 104.56, $p<0.0001$ ). Tukey's test identified significant differences in mean locomotor activity in the Pnx- ${ }^{-} \mathrm{Coc}$ group, compared to the Pnx-S-saL, Pnx-S-coc, and Pnx-sal groups, at ZT4 ( $p<0.003)$, ZT10 ( $p<0.002)$, ZT16 $(p<0.001)$, and ZT22 ( $<0.001)$. Nevertheless, statistical analysis found no differences in locomotor activity in the Pnx- ${ }^{-} \mathrm{OC}$ and the Pnx-sal groups between ZT4 and ZT10 ( $p=0.94)$, at ZT10 compared to ZT16 $(p=0.88)$, or at ZT16 compared to ZT22 $(p=0.95)$ (Figure 3B), respectively.

The post-hoc test did find differences between the PnxS-sAL and PnX-sAL groups at ZT4 $(p<0.001)$ and ZT10 $(p<0.001)$, but not at ZT16 $(p=0.89)$ or ZT22 $(p=0.99)$.

Removal of the pineal glands was confirmed by melatonin ELISA on serum samples collected in the dark period (ZT22), when melatonin levels normally rise. Oneway ANOVA found differences between the groups $\left(\mathrm{F}_{3,31}\right.$ $=9523.908, p<0.0001$ ), and post-hoc analysis revealed differences in plasma melatonin levels in the pinealectomized groups (Pnx-saL and Pnx-COC) compared to the Pnx-S-sAL $(p<0.001)$ and Pnx-S-coc $(p<0.001)$ groups (Figure $3 C$ ).

\section{Experiment 4: Melatonin decreased cocaine-induced locomotor activity in pinealectomized rats}

During the post-Pnx phase, rats in the Pnx-S-SAL+SAL, Pnx-S-SAL+COC, PnX-S-MEL+SAL, and PnX-S-MEL+COC showed alterations in locomotor activity that varied according to the time of the day, as described in the previous experiment. The PnX-SAL + SAL and PnX-MEL+SAL groups showed an increase in locomotor activity, as described in Experiment 3. In contrast, animals subjected to removal of the pineal gland (Pnx-sAL +COC, PnX-MEL $+\mathrm{COC}$ ) experienced an enhanced increase in cocaineinduced locomotor activity at ZT4, ZT10, ZT16, and ZT22. 
Experiment 3

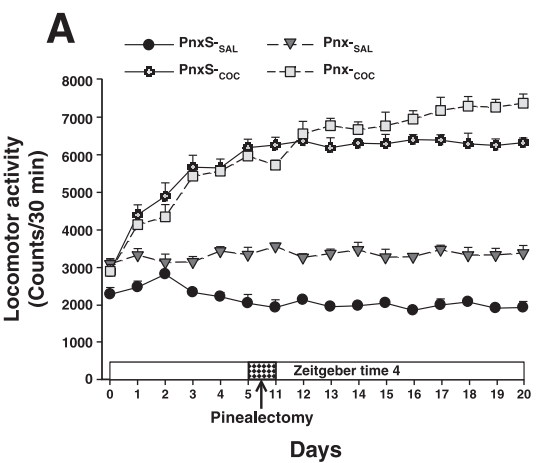

\section{B}
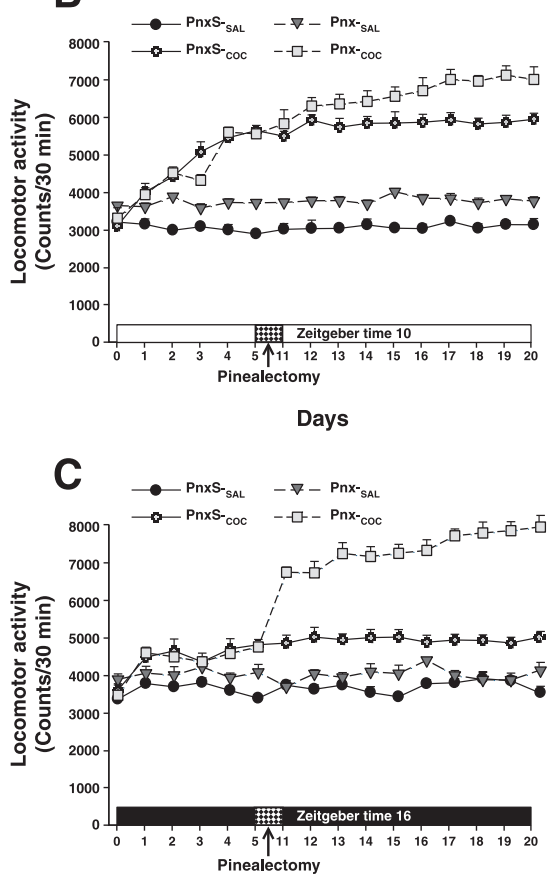

Days

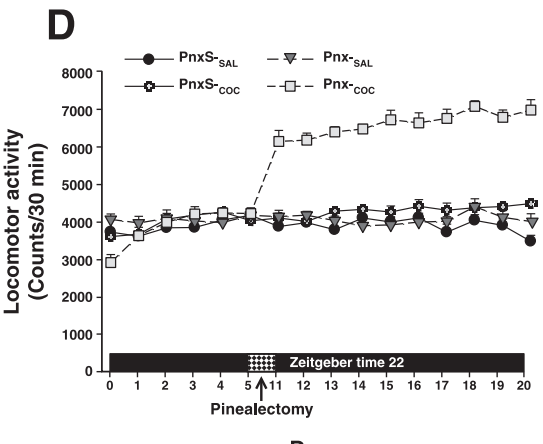

Experiment 4

E

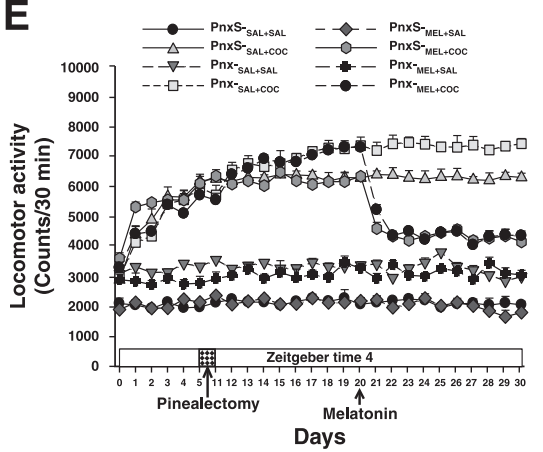

$\mathbf{F}$

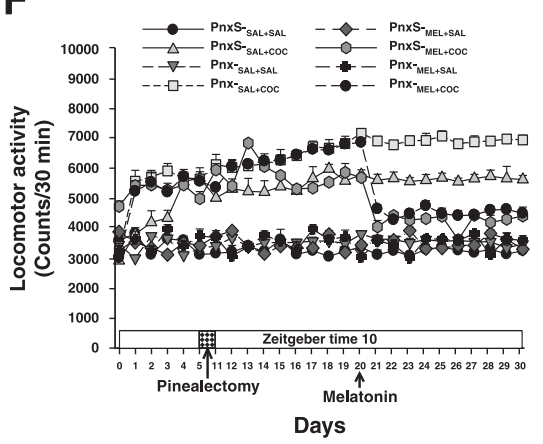

G

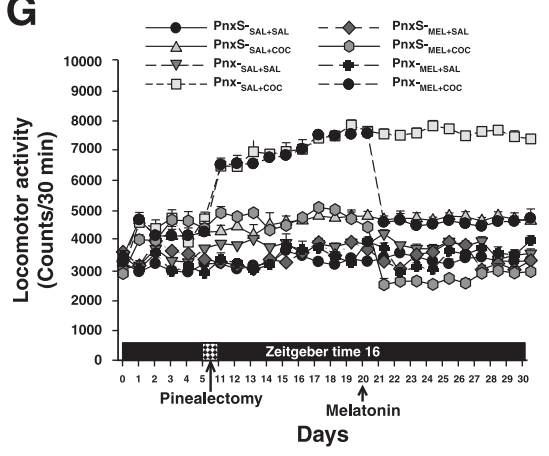

H

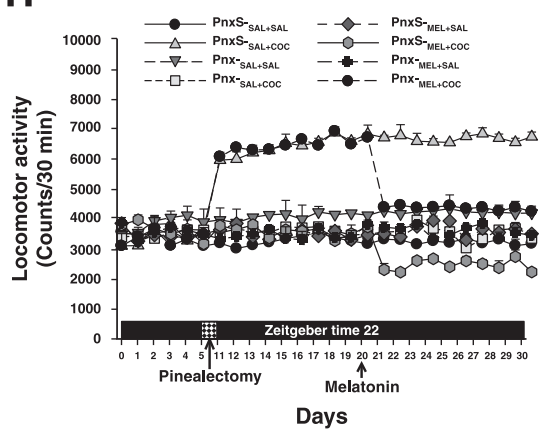

Experiment 5
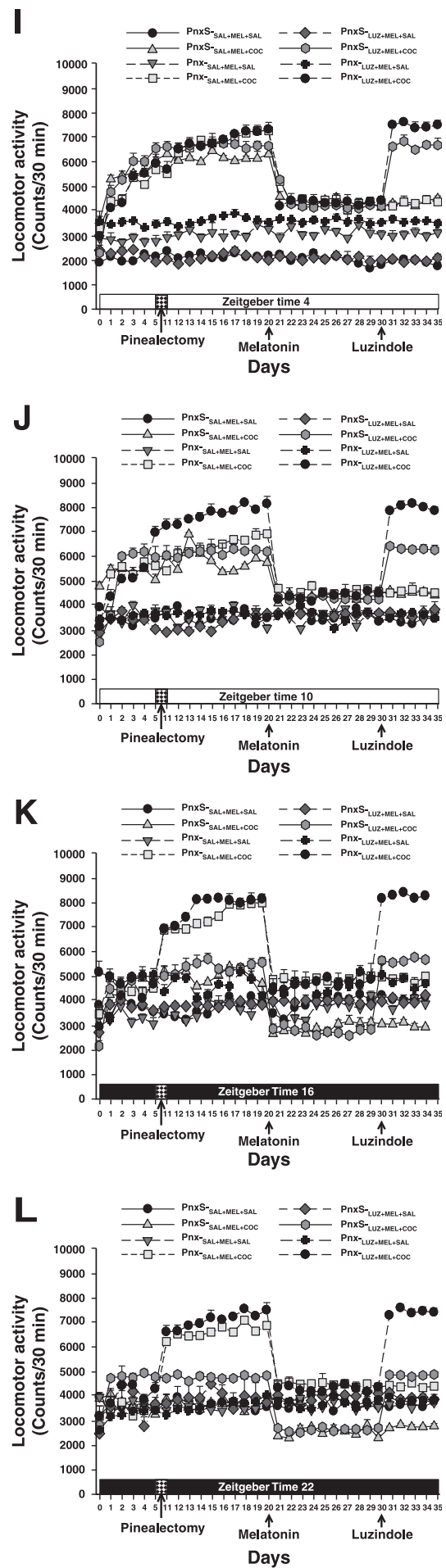

Figure 6 Role of the pineal gland in cocaine-induced locomotor activity. A-D) Experiment 3: Effect of pinealectomy on cocaineinduced locomotor activity at ZT4, ZT10, ZT16, and ZT22, respectively. E-H) Experiment 4: Effect of melatonin on cocaine-induced locomotor activity at ZT4, ZT10, ZT16, and ZT22, respectively. I-L) Experiment 5: Effect of luzindole on cocaine-induced locomotor activity in animals treated with melatonin at ZT4, ZT10, ZT16, and ZT22, respectively. 
During the melatonin phase, administration of melatonin to rats in the PnX-S-MEL+SAL and PnX-MEL + SAL groups did not alter locomotor activity at any of the four time points of assessment. In contrast, daily treatment with melatonin in the PnX-S-MEL + COC and PnX-MEL + COC groups resulted in a decrease in cocaine-induced locomotor activity (Figure 6E to $6 \mathrm{H}$ ).

Four-way ANOVA found differences between group vs. surgery vs. treatment v.s time-of-day interactions $\left(F_{3,2560}\right.$ $=102.43, p<0.0001)$. Tukey's test revealed differences in mean locomotor activity in the PnX-MEL + COC group compared to the Pnx-S-SAL+SAL, PnX-S-SAL+COC, PnXS-MEL+SAL, PnX-SAL+SAL, PnX-MEL +SAL, and PnX-SAL + coc groups at ZT4 $(p<0.003)$, ZT10 $(p<0.002)$, ZT16 $(p<0.004)$, and ZT22 $(p<0.003)$. However, the post-hoc test found no differences in locomotor activity in the PnX-MEL+ COC group compared to the PnX-S-MEL + COC group at ZT4 $(p=0.72)$, and ZT10 $(p=0.97)$ (Figure $4 B)$.

In addition, the statistical analysis did not reveal differences in cocaine-induced locomotor activity in the PnX-MEL + COC group between ZT4-ZT10 and ZT16-ZT22 $(p=0.91)$.

Removal of the pineal glands was confirmed by melatonin ELISA. One-way ANOVA found differences between the groups $\left(F_{7,63}=7538.107, p<0.0001\right)$. The post-hoc analysis revealed differences in plasma melatonin levels in the Pnx-sal+Sal, Pnx-sal+mel, Pnx-coc + COC, and Pnx-COC+MEL groups compared to the PnXS-SAL + SAL $(p<0.001)$, Pnx-S-SAL+MEL $(p<0.001)$, PnXS- ${ }^{C O C}+\operatorname{COC}(p<0.001)$, and PnX-S-COC+MEL $(p<0.001)$ groups (Figure 4C).

\section{Experiment 5: Luzindole blocked melatonin-induced reduction in cocaine-induced locomotor activity in pinealectomized rats}

During the antagonism phase, in the Pnx-S-SAL+MEL+SAL and PnX-S-SAL+MEL+COC groups, locomotor activity depended on the time of day, as described in the previous experiment, where daily melatonin caused a significant decrease in cocaine-induced locomotor activity in pinealectomized animals (the PnX-SAL+MEL+SAL and the PnX-SAL + MEL + COC). In contrast, treatment with luzindole administered prior to melatonin to animals having undergone sham or complete Pnx (Pnx-S-LUZ+MEL+COC and PnX-LUZ + MEL + COC) increased cocaine-induced locomotor activity at ZT4, ZT10, ZT16, and ZT22.

A four-way ANOVA detected differences between group vs. surgery vs. treatment vs. time-of-day interactions $\left(F_{3,320}=14.410, p<0.0001\right)$. Tukey's test found differences in mean locomotor activity in PnX-S-LUZ+MEL+COC and PnX-LUZ+MEL + COC compared to PnX-S-SAL+ MEL + SAL, PnXS-SAL+MEL+COC, PnX-SAL+MEL+ SAL, PnX-SAL + MEL + COC, PnX-S-SAL+LUZ+MEL, and PnX-LUZ+MEL+SAL at ZT4 ( $p<$ $0.003)$, ZT10 ( $p<0.002)$, ZT16 ( $<<0.002)$, and ZT22 $(p<0.004$; Figure 5B). This suggests that the decrease in locomotor activity in animals treated with melatonin was due to its action on the $\mathrm{MT}_{1}$ and $\mathrm{MT}_{2}$ melatonin receptors.

Removal of the pineal glands was confirmed by melatonin ELISA. One-way ANOVA found differences between the groups $\left(F_{7,63}=9438.332, p<0.0001\right)$. Post-hoc analysis revealed differences in plasma melatonin levels $(p<0.001)$ similar to those found in the previous experiment (Figure 5C).

\section{Discussion}

Diurnal differences in cocaine-induced locomotor activity

Several studies have reported that, in rats and mice, the behavioral effects of cocaine, ${ }^{6,7}$ nicotine, $^{8}$ and alcohol ${ }^{30}$ depend on the time of day of administration. ${ }^{6,38}$ These studies have found a strong behavioral sensitization response to cocaine in the early morning, during the light phase (ZT4), and a decrease at the end of the light phase (ZT12), reaching its lowest levels at the end of the dark phase (ZT20). ${ }^{38}$

Additionally, day/night variations have been described in the reinstatement of cocaine-induced CPP ${ }^{10,11}$ and in cocaine self-administration. ${ }^{12}$

These results are consistent with those of this study. Locomotor activity increased at the beginning of the light phase (ZT4) and decreased at the end of the dark phase (ZT22).

Some authors have reported that this increase in cocaine-induced locomotor activity is due to higher dopamine release. ${ }^{39}$ Other researchers have suggested that dopamine plays an important role in the relationship between drug reward and circadian rhythms. ${ }^{40}$ These studies have described diurnal fluctuations in extracellular dopamine levels in the dorsal striatum, which peak during the active phase. ${ }^{13,14}$ They have also described diurnal and circadian variations in DAT levels, ${ }^{15} \mathrm{DC},{ }^{16}$ expression and function of $\mathrm{TH}^{15}$ and monoamine oxidase A (MAO) enzyme in the VTA and NAcc in rats, with greater expression during the light phase (ZT4-6) than during the dark phase (ZT16-20). ${ }^{40}$

This suggests that the diurnal variations in cocaineinduced locomotor activity described herein may be the result of diurnal variations in the previously described elements of the dopaminergic system.

Nonetheless, a strong link between the light cycle and behavioral responses to cocaine has been suggested. ${ }^{41}$ Sorg et al. ${ }^{41}$ reported that changes in the proportion of light during the day (photoperiod) modulated different cocaine behavioral responses. They also found that exposure of rats to short photoperiods suppressed reinstatement of cocaine-induced CPP and altered the levels of DAT and TH protein in the PFC. On the other hand, long photoperiods did not alter the reinstatement of cocaineinduced CPP. ${ }^{41}$

Several studies have found that $\mathrm{C} 3 \mathrm{H} 7 \mathrm{HeN}$ mice show cocaine-induced locomotor sensitization in the light phase, but not during the dark phase. ${ }^{10,29}$ This diurnal variation in cocaine-induced locomotor sensitization has been associated with diurnal fluctuations in melatonin levels. ${ }^{19}$ In $\mathrm{C} 3 \mathrm{H} 7 \mathrm{HeN}$ mice, the highest levels of melatonin occur during the dark phase and the lowest levels are observed in the light phase, when cocaine enhances locomotor activity. ${ }^{10,29}$ This diurnal variation, however, is not observed in C57BL/6J mice, which are considered 
melatonin-deficient. ${ }^{11}$ This suggests a potential link between nocturnal melatonin and the lack of cocaineinduced locomotor activity during the dark phase. ${ }^{17}$

\section{Continuous lighting increased cocaine-induced locomotor activity}

Our study found that exposure to L/L caused: 1) a loss of circadian variations in cocaine-induced locomotor activity; 2) decreased serum melatonin levels; and 3) increased cocaine-induced locomotor activity.

These results are in line with previous results indicating that exposure to $\mathrm{L} / \mathrm{L}$ decreases serum melatonin levels ${ }^{42}$ and enhances the psychostimulant effects of cocaine, while altering different rhythms ${ }^{43}$; that is, under L/L, the diurnal rhythm of cocaine self-administration is fragmented and animals consume significantly less cocaine. ${ }^{43}$ In male Wistar rats, 1 month of exposure to L/L exerted a significant effect on voluntary morphine consumption, increased severity of naloxone-induced withdrawal symptoms, and was associated with upregulation of Per1, Per2, and $D_{1}$ dopamine receptor mRNA expression levels in the striatum and PFC. ${ }^{9}$

The circadian changes associated with continuous exposure to light, known as functional Pnx, are the result of a decrease in endogenous circulating melatonin levels. ${ }^{42}$ This leads to pathophysiological changes, metabolic disruption, endocrine malfunction, and increased free radicals, which, in turn cause molecular damage and abnormal behaviors. ${ }^{42}$ Moreover, constant light disrupts the circadian rhythms of spontaneous locomotor activity, increases anxiety- and depressive-like behaviors, and impairs shortterm memory. ${ }^{42,44}$

On the other hand, animals exposed to constant dark conditions show a circadian rhythm of reinstatement of cocaine-induced CPP, cocaine self-administration, and melatonin release. ${ }^{41}$ This suggests that continuous lighting increases the likelihood of consumption of such drugs as cocaine and morphine, mainly due to a decrease in plasma levels of melatonin.

\section{Pinealectomy increased cocaine-induced locomotor activity}

Several studies have described the effects of Pnx on mice. ${ }^{10,29}$ As mentioned above, in $\mathrm{C} 3 \mathrm{H} 7 \mathrm{HeN}$ mice, cocaineinduced locomotor sensitization and CPP decrease during the dark phase. ${ }^{11,29}$ This diurnal variation is eliminated with removal of the pineal gland, ${ }^{10,29}$ which is also the case specifically for Per1 gene expression in C3H7HeJ pinealectomized mice. ${ }^{29}$ Additionally, pineal gland removal decreases plasma levels of melatonin in rats and mice. ${ }^{14}$

Our study found similar results. In pinealectomized rats, cocaine-induced locomotor activity increased at the times of the day we evaluated, and there was a loss of diurnal variation. Additionally, removal of the pineal gland also decreased serum melatonin levels, as in previous experiments. ${ }^{20,21}$

Several studies have reported the putative effects of melatonin and the pineal gland on the dopaminergic system. $^{26}$ Melatonin reduces dopamine content, replacement, and release, and enhances the affinity of $D_{2}$ dopamine receptors. ${ }^{45}$ Since cocaine increases dopamine release in the NAcc and VTA ${ }^{39}$ and melatonin negatively regulates the dopaminergic system, ${ }^{24}$ potentiation of cocaine-induced locomotor activity in pinealectomized animals is likely due to a lack of negative regulation of the dopaminergic system by melatonin.

\section{Melatonin decreased cocaine-induced locomotor activity in pinealectomized rats}

In this study, we found that melatonin administration prior to cocaine administration in naïve or pinealectomized rats significantly decreased cocaine-induced locomotor activity at different times of day (ZT4, ZT10, ZT16, and ZT22).

In a pioneering study, Sircar ${ }^{36}$ found that acute melatonin dosing of naïve Sprague-Dawley rats decreased cocaine sensitization. These results are in line with ours: naïve rats Wistar that received melatonin showed a significant decrease in cocaine-induced locomotor activity at different times of day. Still, a major difference between the Sincar ${ }^{36}$ study and ours is that we did not evaluate the effect of exogenous melatonin at different times of day.

Melatonin levels measured by ELISA were lower in rats subjected to surgical removal of the pineal gland. However, even in these animals, administration of exogenous melatonin was able to decrease cocaine-induced locomotor activity. Several researchers have reported that the removal of the pineal gland does not alter the density of melatonin receptors ${ }^{46-48}$; this correlates with our finding that exogenous melatonin decreased cocaine-induced locomotor activity in pinealectomized animals, probably because of its action on the $\mathrm{MT}_{1}$ and the $\mathrm{MT}_{2}$ melatonin receptors in the striatum. ${ }^{24}$

Various studies have described the role of the $\mathrm{MT}_{1}$ and $\mathrm{MT}_{2}$ melatonin receptors in the modulation of responses to drugs of abuse. ${ }^{28} \mathrm{MT}_{1}$ and $\mathrm{MT}_{2}$ gene knockdown prevents the development and expression of methamphetamine-induced locomotor sensitization and CPP in melatonin-expressing $\mathrm{C} 3 \mathrm{H} / \mathrm{HeN}$ and low-melatonin-expressing C57BL/6J mice. ${ }^{28}$ In addition, Uz et al. ${ }^{24}$ reported that the $\mathrm{MT}_{1}$ - but not the $\mathrm{MT}_{2}$ - receptors are necessary for cocaine-induced locomotor sensitization in rodents. ${ }^{24,25}$

It was recently reported elsewhere that melatonin decreased cocaine self-administration in rats ${ }^{26}$ and modulated alcohol-seeking and decreased alcohol relapse-like behaviors in rats. ${ }^{30}$

\section{Luzindole blocked melatonin-induced reduction in cocaine-induced locomotor activity in pinealectomized rats}

Several studies have described the effect of luzindole (an $\mathrm{MT}_{1}$ and $\mathrm{MT}_{2}$ melatonin receptor antagonist) on melatonin-induced behavior. ${ }^{49} \mathrm{Han}$ et al. ${ }^{49}$ reported that systemic or intracerebral administration of 25 or $50 \mathrm{mg} / \mathrm{kg}$ melatonin to KM mice prevented the expression of morphine-induced CPP; this effect was reversed by treatment with luzindole. These results are consistent with those obtained in the present study. Administration of luzindole to naïve or pinealectomized rats treated with 
melatonin blocked the effect of melatonin and increased cocaine-induced locomotor activity.

As mentioned above, melatonin modulates dopamine release through its $M T_{1}$ and $\mathrm{MT}_{2}$ receptors in the dopaminergic system. ${ }^{19,50}$ Such decrease - likely the effect of melatonin administration on cocaine-induced locomotor activity in pinealectomized animals in this study - was the result of the activation of $\mathrm{MT}_{1}$ and $\mathrm{MT}_{2}$ receptors in the striatum. This is demonstrated by the fact that use of luzindole, an $\mathrm{MT}_{1}$ and $\mathrm{MT}_{2}$ receptor antagonist blocked the effect of melatonin and restored the effect of cocaine on locomotor activity at the different times of the day evaluated in this study.

Drugs of abuse, such as cocaine, disrupt various behavioral and physiological rhythms. ${ }^{4}$ Further, administration of melatonin significantly decreases the reinforcing effects of cocaine in rodents, ${ }^{36}$ probably by modulating the dopaminergic system through its $\mathrm{MT}_{1}$ and $\mathrm{MT}_{2}$ receptors. ${ }^{19}$

Several studies have described the role of clock genes in addiction in rodents and humans. ${ }^{51}$ Exposure to drugs of abuse such as cocaine disrupts expression of the period, clock, and npas 2 genes, all of which are so-called core clock genes - part of a conserved transcriptionaltranslational feedback loop known as the molecular clock, which is responsible for generating biological rhythms in the body. ${ }^{52,53}$ In mice, a negative mutation in the clock, per1, or per2 genes causes loss in diurnal and circadian rhythmicity in cocaine-induced self-administration, locomotor sensitization, and CPP. ${ }^{6,54}$ Additionally, other studies have shown that clock genes regulate dopaminergic function, ${ }^{2,50}$ while others have shown that melatonin modulates the expression of clock genes. ${ }^{3}$ This suggests that the decrease in function of the period, clock, and $n \mathrm{pas}_{2}$ genes increases vulnerability to cocaine abuse by reducing behavioral rhythmicity, increasing dopaminergic function, and increasing drug abuse during the day. In turn, melatonin, through its receptors in the dopaminergic system, may restore the rhythmic expression of the clock genes, thus weakening the reinforcing effect of cocaine. ${ }^{25,50}$

In this study, we found that melatonin decreased cocaine-induced locomotor activity in naïve and pinealectomized rats at different times of the day. Given the ability of melatonin to mitigate various reinforcing effects of cocaine at different times of day, melatonin could be a useful therapeutic agent to reduce cocaine abuse.

\section{Acknowledgements}

This study was carried out thanks to grant INP-2040 and support from Consejo Nacional Contra las Adicciones (CONADIC) and the Gonzalo Ríos Arronte Foundation.

\section{Disclosure}

The authors report no conflicts of interest.

\section{References}

1 O'Brien CP. Neuroplasticity in addictive disorders. Dialogues Clin Neurosci. 2009;11:350-3.
2 Hood S, Cassidy P, Cossette MP, Weigl Y, Verwey M, Robinson B, et al. Endogenous dopamine regulates the rhythm of expression of the clock protein PER2 in the rat dorsal striatum via daily activation of D2 dopamine receptors. J Neurosci. 2010;30:14046-58.

3 Christ E, Pfeffer M, Korf HW, von Gall C. Pineal melatonin synthesis is altered in Period1 deficient mice. Neuroscience. 2010;171: 398-406.

4 Kim J, Jang S, Choe HK, Chung S, Son GH, Kim K. Implications of circadian rhythm in dopamine and mood regulation. Mol Cells. 2017;40:450-6.

5 Sandyk R, Kanofsky JD. Cocaine addiction: relationship to seasonal affective disorder. Int J Neurosci. 1992;64:195-201.

6 Abarca C, Albrecht U, Spanagel R. Cocaine sensitization and reward are under the influence of circadian genes and rhythm. Proc Natl Acad Sci U S A. 2002;99:9026-30.

7 Akhisaroglu M, Ahmed R, Kurtuncu M, Manev H, Uz T. Diurnal rhythms in cocaine sensitization and in Period1 levels are common across rodent species. Pharmacol Biochem Behav. 2004;79:37-42.

8 Mexal S, Horton WJ, Crouch EL, Maier SI, Wilkinson AL, Marsolek M, et al. Diurnal variation in nicotine sensitivity in mice: role of genetic background and melatonin. Neuropharmacology. 2012;63:966-73.

9 Garmabi B, Vousooghi N, Vosough M, Yoonessi A, Bakhtazad A, Zarrindast MR. Effect of circadian rhythm disturbance on morphine preference and addiction in male rats: involvement of period genes and dopamine D1 receptor. Neuroscience. 2016;322:104-14.

10 Kurtuncu M, Arslan AD, Akhisaroglu M, Manev H, Uz T. Involvement of the pineal gland in diurnal cocaine reward in mice. Eur $\mathrm{J}$ Pharmacol. 2004;489:203-5.

$11 \mathrm{Uz} \mathrm{T}, \mathrm{Qu} \mathrm{T}$, Sugaya K, Manev H. Neuronal expression of arylalkylamine $\mathrm{N}$-acetyltransferase (AANAT) mRNA in the rat brain. Neurosci Res. 2002;42:309-16.

12 Baird TJ, Gauvin D. Characterization of cocaine self-administration and pharmacokinetics as a function of time of day in the rat. Pharmacol Biochem Behav. 2000;65:289-99.

13 Castañeda TR, de Prado BM, Prieto D, Mora F. Circadian rhythms of dopamine, glutamate and GABA in the striatum and nucleus accumbens of the awake rat: modulation by light. J Pineal Res. 2004;36:177-85.

14 Khaldy H, León J, Escames G, Bikjdaouene L, García JJ, AcuñaCastroviejo D. Circadian rhythms of dopamine and dihydroxyphenyl acetic acid in the mouse striatum: effects of pinealectomy and of melatonin treatment. Neuroendocrinology. 2002;75:201-8.

15 Sleipness EP, Sorg BA, Jansen HT. Diurnal differences in dopamine transporter and tyrosine hydroxylase levels in rat brain: dependence on the suprachiasmatic nucleus. Brain Res. 2007;1129:34-42.

16 Sleipness EP, Jansen HT, Schenk JO, Sorg BA. Time-of-day differences in dopamine clearance in the rat medial prefrontal cortex and nucleus accumbens. Synapse. 2008;62:877-85.

17 Liu J, Clough SJ, Hutchinson AJ, Adamah-Biassi EB, Popovska-Gorevski M, Dubocovich ML. MT1 and MT2 melatonin receptors: a therapeutic perspective. Annu Rev Pharmacol Toxicol. 2016;56:361-83.

18 Hirsch-Rodriguez E, Imbesi M, Manev R, Uz T, Manev H. The pattern of melatonin receptor expression in the brain may influence antidepressant treatment. Med Hypotheses. 2007;69:120-4.

19 Imbesi M, Uz T, Yildiz S, Arslan AD, Manev H. Drug- and regionspecific effects of protracted antidepressant and cocaine treatment on the content of melatonin MT(1) and MT(2) receptor mRNA in the mouse brain. Int J Neuroprot Neuroregener. 2006;2:185-9.

20 Chen L, Zhou T, Wu N, O'Brien A, Venter J, Ceci L, et al. Pinealectomy or light exposure exacerbates biliary damage and liver fibrosis in cholestatic rats through decreased melatonin synthesis. Biochim Biophys Acta Mol Basis Dis. 2019;1865:1525-39.

21 Tasdemir S, Samdanci E, Parlakpinar H, Polat A, Tasdemir C, Cengiz $\mathrm{N}$, et al. Effects of pinealectomy and exogenous melatonin on the brains, testes, duodena, and stomachs of rats. Eur Rev Med Pharmacol Sci. 2012;16:860-6.

22 Jockers R, Delagrange P, Dubocovich ML, Markus RP, Renault N, Tosini G, et al. Update on melatonin receptors: IUPHAR Review 20. Br J Pharmacol. 2016;173:2702-25.

$23 \mathrm{Ng} \mathrm{KY}$, Leong MK, Liang H, Paxinos G. Melatonin receptors: distribution in mammalian brain and their respective putative functions. Brain Struct Funct. 2017;222:2921-39.

$24 \mathrm{Uz} T$, Arslan AD, Kurtuncu M, Imbesi M, Akhisaroglu M, Dwivedi $\mathrm{Y}$, et al. The regional and cellular expression profile of the melatonin 
receptor MT1 in the central dopaminergic system. Brain Res Mol Brain Res. 2005;136:45-53.

25 Imbesi M, Arslan AD, Yildiz S, Sharma R, Gavin D, Tun N, et al. The melatonin receptor MT1 is required for the differential regulatory actions of melatonin on neuronal 'clock' gene expression in striatal neurons in vitro. J Pineal Res. 2009;46:87-94.

26 Takahashi TT, Vengeliene V, Spanagel R. Melatonin reduces motivation for cocaine self-administration and prevents relapse-like behavior in rats. Psychopharmacology (Berl). 2017;234:1741-8.

27 Horton WJ, Gissel HJ, Saboy JE, Wright KP Jr, Stitzel JA. Melatonin administration alters nicotine preference consumption via signaling through high-affinity melatonin receptors. Psychopharmacology (Berl). 2015;232:2519-30.

28 Wu J, Zhu D, Zhang J, Li G, Liu Z, Sun J. Melatonin treatment during the incubation of sensitization attenuates methamphetamine-induced locomotor sensitization and MeCP2 expression. Prog Neuropsychopharmacol Biol Psychiatry. 2016;65:145-52.

29 Uz T, Akhisaroglu M, Ahmed R, Manev $\mathrm{H}$. The pineal gland is critical for circadian Period1 expression in the striatum and for circadian cocaine sensitization in mice. Neuropsychopharmacology. 2003;28:2117-23.

30 Vengeliene V, Noori HR, Spanagel R. Activation of melatonin receptors reduces relapse-like alcohol consumption. Neuropsychopharmacology. 2015;40:2897-906.

31 Barbosa-Méndez S, Matus-Ortega M, Flores-Zamora A, Jurado N, Salazar-Juárez A. Dose- and time-dependent effects of mirtazapine on the expression of cocaine-induced behavioral sensitization in rats. Psychiatry Res. 2017;254:301-10.

32 Barbosa-Méndez S, Salazar-Juárez A. Cocaine + nicotine mixture enhances induction and expression of behavioral sensitization in rats. J Psychiatr Res. 2018;100:88-98.

33 Barbosa-Méndez S, Matus-Ortega M, Jacinto-Gutiérrez S, SalazarJuárez A. Mirtazapine impairs acquisition and reinstatement of cocaine-induced place preference in rats. Eur J Pharmacol. 2018; 820:183-90.

34 Barbosa-Méndez S, Matus-Ortega M, Salazar-Juárez A. Synergistic interactions between mirtazapine and prazosin prevent the induction and expression of behavioral sensitization to cocaine in rats. Physiol Behav. 2017;180:137-45

35 Salazar-Juárez A, Barbosa-Méndez S, Jurado N, Hernández-Miramontes $\mathrm{R}$, Leff $\mathrm{P}$, Antón B. Mirtazapine prevents induction and expression of cocaine-induced behavioral sensitization in rats. Prog Neuropsychopharmacol Biol Psychiatry. 2016;68:15-24.

36 Sircar R. Effect of melatonin on cocaine-induced behavioral sensitization. Brain Res. 2000;857:295-9.

37 Dubocovich ML, Mogilnicka E, Areso PM. Antidepressant-like activity of the melatonin receptor antagonist, luzindole $(\mathrm{N}-0774)$, in the mouse behavior despair test. Eur J Pharmacol. 1990;182:313-25.

38 Sleipness EP, Sorg BA, Jansen HT. Time of day alters long-term sensitization to cocaine in rats. Brain Res. 2005;1065:132-7.
39 Kalivas PW, Duffy P. Time course of extracellular dopamine and behavioral sensitization to cocaine. I. Dopamine axon terminals. J Neurosci. 1993;13:266-75.

40 Webb IC, Baltazar RM, Wang X, Pitchers KK, Coolen LM, Lehman MN. Diurnal variations in natural and drug reward, mesolimbic tyrosine hydroxylase, and clock gene expression in the male rat. J Biol Rhythms. 2009;24:465-76.

41 Sorg BA, Stark G, Sergeeva A, Jansen HT. Photoperiodic suppression of drug reinstatement. Neuroscience. 2001;176:284-95.

42 Wideman $\mathrm{CH}$, Murphy $\mathrm{HM}$. Constant light induces alterations in melatonin levels, food intake, feed efficiency, visceral adiposity, and circadian rhythms in rats. Nutr Neurosci. 2009;12:233-40.

43 Oxenkrug GF, Dragovic LJ, Marks BH, Yuwiler A. Effect of cocaine on rat pineal melatonin synthesis in vivo and in vitro. Psychiatry Res. 1990;34:185-91.

44 Voiculescu SE, Le Duc D, Roşca AE, Zeca V, Chiţimuş DM, Arsene $A L$, et al. Behavioral and molecular effects of prenatal continuous light exposure in the adult rat. Brain Res. 2016;1650:51-9.

45 Jaliffa CO, Lacoste FF, Llomovatte DW, Sarmiento MI, Rosenstein RE. Dopamine decreases melatonin content in golden hamster retina. J Pharmacol Exp Ther. 2000;293:91-5.

46 Gauer $F$, Masson-Pévet M, Pévet P. Differential regulation of melatonin receptors by short- versus long-term pinealectomy in the rat suprachiasmatic nuclei and pars tuberalis. J Pineal Res. 1994;16:73-6.

47 Gauer F, Masson-Pévet M, Pévet P. Effect of constant light, pinealectomy and guanosine triphosphate gamma-s on the density of melatonin receptors in the rat suprachiasmatic nucleus: a possible implication of melatonin action. J Neuroendocrinol. 1992;4:455-9.

48 Gauer F, Masson-Pévet M, Pévet P. Pinealectomy and constant illumination increase the density of melatonin binding sites in the pars tuberalis of rodents. Brain Res. 1992;575:32-8.

49 Han J, Xu Y, Yu CX, Shen J, Wei YM. Melatonin reverses the expression of morphine-induced conditioned place preference through its receptors within central nervous system in mice. Eur J Pharmacol. 2008;594:125-31.

50 Imbesi M, Yildiz S, Dirim-Arslan A, Sharma R, Manev H, Uz T. Dopamine receptor-mediated regulation of neuronal "clock" gene expression. Neuroscience. 2009;158:537-44.

51 Falcon E, Ozburn A, Mukherjee S, Roybal K, McClung CA. Differential regulation of the period genes in striatal regions following cocaine exposure. PLoS One. 2013;8:e66438.

52 Jagannath A, Taylor L, Wakaf Z, Vasudevan SR, Foster RG. The genetics of circadian rhythms, sleep and health. Hum Mol Genet. 2017;26:R128-38.

53 Wei K, Wang Q, Gan J, Zhang S, Ye M, Gragnoli C, et al. Mapping genes for drug chronotherapy. Drug Discov Today. 2018;23:1883-8.

54 Ozburn AR, Larson EB, Self DW, McClung CA. Cocaine selfadministration behaviors in Clock $\Delta 19$ mice. Psychopharmacology (Berl). 2012;223:169-77. 